\title{
SPATIAL DISTRIBUTION OF WEED SEEDBANK IN MAIZE CROPPING FIELDS
}

\author{
A. RAHMAN, T.K. JAMES, N. GRBAVAC ${ }^{1}$ and J. MELLSOP \\ AgResearch, Ruakura Agricultural Research Centre, Private Bag 3123, Hamilton \\ ${ }^{1}$ MAFQual, Official Seed Testing Station, PO Box 609, Palmerston North
}

\begin{abstract}
Seedbank species and density in inner and outer parts of six maize fields were estimated by methods of seed extraction and seedling emergence. There was a positive correlation between the two methods. Most of the 68 weed species recorded were present in low numbers and less than half were common to all sites. There were large variations between samples within each site. No significant differences were found in the number of seeds or seedlings between samples collected from inner and outer areas of the fields, but samples from the outer areas grew seedlings of significantly more weed species. This greater biodiversity of field edges has implications for sampling for weed seedbank estimates.
\end{abstract}

Keywords: seedbank, seedling emergence, seed extraction, weed seeds, field margins

\section{INTRODUCTION}

The weed seedbank is the reservoir of weed seeds in the soil or on the soil surface and it largely determines the species composition and potential densities of weeds that subsequently interfere with crops during the growing season. A number of problems are inherent in the estimation of the true seedbank size of an arable weed with an annual life cycle. Weed seedbanks are notoriously variable (Benoit et al. 1992); it is necessary to collect multiple soil cores and sample from different locations within a field in order to get a reliable estimate of the weed seed population (Dessaint et al. 1990; Forcella et al. 1992). Casual observations suggest that the edges and corners of arable fields tend to be the areas of greatest botanical diversity. This may apply to relatively common species, although it is possible that rarer species also share this distribution.

Determination of the density of viable weed seeds in a soil sample is a tedious and slow process. The usual techniques employed use either of two methods: direct seed extraction or glasshouse seedling emergence. These methods have several advantages and disadvantages and our work has indicated that both gave similar estimates of grass weeds but the seed extraction method generally found more broadleaf weed seeds (Rahman et al. 1995). This study also showed a high ratio of seedlings emerged to seeds enumerated, which, demonstrated the potential for using the weed seed content of the soil to predict future weed problems in the field which would be valuable for planning crop sequences and herbicide usage.

In order to exploit the potential of using the weed seed content in the soil to predict future weed problems, studies were conducted to examine the distribution of arable weed seeds in inner and outer areas of different maize fields and to further evaluate the two methods of estimating the weed seedbank in the soil.

\section{MATERIALS AND METHODS}

Six fields in Waikato that had been used for growing maize for several years were selected. The fields had a variety of soil types ranging from peaty loam soils to clay soils. Each field was divided into eight areas for sampling according to Fig. 1, and notes made as to the position of strategic features such as drains, hedgerows, etc. The outer area was always $20 \mathrm{~m}$ wide and generally conformed to the headland planting 
area for the maize crop. Each area was sampled by taking a total of 60 cores along several transects using a $25 \mathrm{~mm}$ diameter soil corer set to $100 \mathrm{~mm}$ depth. The samples were collected after harvest of the maize crop but before cultivation, in August 1995. The cores were mixed while still field moist and then subsampled. From each sample $1.7-2.3 \mathrm{~kg}$ of soil was used immediately for enumeration by the weed emergence method and the rest was dried at $80^{\circ} \mathrm{C}$ for $4-5$ hours, after which $500 \mathrm{~g}$ of soil was sent to the MAFQual Official Seed Testing Station (OSTS) at Palmerston North, for enumeration by the seed extraction method.

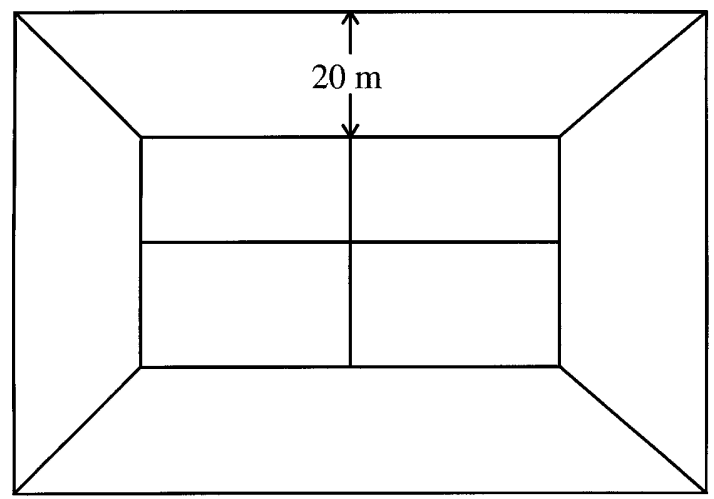

FIGURE 1: Division of each field into four outer and four inner sampling areas.

Both enumeration methods have been described previously (Rahman et al. 1995). Briefly, the seedling emergence method involved five repeat incubations of each soil sample followed by 2 months chilling at $4{ }^{\circ} \mathrm{C}$ and a further two incubations. These incubations were carried out in a glasshouse over summer with temperatures ranging from $10^{\circ} \mathrm{C}$ at night to $35^{\circ} \mathrm{C}$ during the day. The soil was laid out in trays $(30 \mathrm{x} 40 \mathrm{x}$ $4 \mathrm{~cm}$ ) over a bed of vermiculite and water was added as required to keep the sample moist. For the seed extraction method, the samples were first washed through a fine mesh to remove the fine soil particles. The remaining contents of the bag were dried and then passed through a descending series of sieves. Whole seeds from each sieving were then extracted by hand, counted and identified. Seed viability was determined by crushing the seed and inspecting the endosperm.

Means and standard deviations were obtained for each species at each site. For spatial distribution, analysis of variance was carried out on the averaged data (inner vs outer) using sites as replicates. Also, areas that were adjacent to special features (drains, hedgerows etc.) were compared to similar featureless areas.

\section{RESULTS AND DISCUSSION}

In the total of seven incubations, the seedling emergence method found 57 different weed species in numbers ranging from 1 - 695/kg dry soil. The seed extraction method recorded a total of 47 species of potentially viable weed seed in quantities ranging from $1-658 / \mathrm{kg}$ dry soil. However, many of the species found by both methods were in quantities that were too small to analyse. The 14 most common and abundant weed species encountered are listed in Table 1, along with the number of seedlings recorded in the glasshouse. The list is divided into three groups. Group 1 included summer broadleaf weeds and comprisedAmaranthus spp., fathen (Chenopodium album), willow weed (Polygonum persicaria) and black nightshade (Solanum nigrum). Group 2 consisted of annual summer grasses, viz. summer grass (Digitaria sanguinalis), smooth witchgrass (Panicum dichotomiflorum) and barnyard grass (Echinochloa crus-galli). Group 3 
comprised the winter/spring weeds, viz., twin cress (Coronopus didymus), hawksbeard (Crepis capillaris), docks (Rumex spp.), dandelion (Taraxacum officinale), clovers (Trifolium spp.) and annual poa (Poa annua). Included in Group 3 is toad rush (Juncus bufonius) which was present in large numbers at all sites. This list of most abundant species is similar to that recorded in earlier studies in the Waikato region (Rahman and James 1993; Rahman et al. 1995), although the numbers in both previous studies were considerably larger, most likely because the sites were freshly cultivated out of pasture or had a varied cropping history. Continuous cropping with maize and the associated use of herbicides appears to have markedly reduced the seedbank of all common weeds, except fathen, possibly due to its increased tolerance/resistance of triazine herbicides used in maize crops (Rahman 1988).

TABLE 1: Emergence of the most abundant weed species found at each site (average of eight areas/site).

\begin{tabular}{lrrrrrr}
\hline & \multicolumn{7}{c}{ Seedling emergence (No./kg dry soil) } \\
Weed species & Site1 & Site 2 & Site 3 & Site 4 & Site 5 & Site 6 \\
\hline Summer broadleaf & & & & & & \\
Amaranthus spp. & 3.4 & 1.0 & 4.3 & 0.7 & 0.8 & 0.3 \\
Fathen & 5.5 & 10.3 & 382.2 & 20.2 & 30.8 & 37.4 \\
Willow weed & 1.0 & 1.6 & 5.3 & 1.3 & 0.7 & 0.1 \\
Black nightshade & 3.1 & 2.7 & 2.4 & 45.9 & 2.7 & 8.7 \\
Summer grasses & & & & & & \\
Summer grass & 8.7 & 13.9 & 14.9 & 16.7 & 8.1 & 1.3 \\
Smooth witchgrass & 5.7 & 12.1 & 9.8 & 4.1 & 7.3 & 0.9 \\
Barnyard grass & 0 & 0.2 & 6.5 & 0.6 & 4.2 & 1.8 \\
Winter/spring weeds & & & & & & \\
Twin cress & 3.5 & 1.4 & 3.9 & 0.3 & 0.7 & 1.2 \\
Hawksbeard & 2.0 & 0.3 & 1.2 & 0.1 & 0 & 1.1 \\
Docks & 3.0 & 5.3 & 6.4 & 15.8 & 1.9 & 4.8 \\
Dandelion & 0.2 & 0.7 & 0.2 & 0.2 & 0.1 & 0.1 \\
Clovers & 1.1 & 1.1 & 0.2 & 1.4 & 0.6 & 0.3 \\
Annual poa & 1.8 & 1.7 & 0.6 & 0 & 0.2 & 0 \\
Toad rush & 41.1 & 52.9 & 36.4 & 7.5 & 11.3 & 12.2 \\
\hline
\end{tabular}

${ }^{\text {a }}$ Standard deviations ranged from $60-100 \%$.

Data from both the seed extraction and the seedling emergence methods indicated that many weed species, including those listed in Table 1 , were common to most sites. Three weeds present in large numbers were fathen, summer grass and smooth witchgrass, probably because all these are often poorly controlled by the current herbicide regimes used by Waikato maize growers (Rahman 1988). No obvious differences were noted in the weed density between sites due to the soil type, despite the range of soils surveyed both in terms of texture and organic matter (except for fathen at Site 3, due to atrazine resistance). This may be a result of continuous maize cropping and use of herbicides on all the sites included in this study. There were large variations, however, between samples within each site (which is reflected in the large standard deviations for the data in Table 1) despite the 60 cores taken along several transects for each sample. This shows a large degree of inherent variation in the weed seedbank of annual cropping systems. It has been suggested that such considerable variation over small distances could be a consequence of the distribution of seedparents in previous seasons (Bigwood and Inouye 1988). Based on sophisticated statistical analyses Dessaint et al. (1990) indicated that hundreds of cores may be necessary to adequately sample seedbanks. It has been suggested by others, however (e.g. Forcella et al. 1992) that for practical purposes, 10 - 20 cores, each $5 \mathrm{~cm}$ diameter, are probably sufficient for a single field or management unit. 
A comparison of the two methods of estimating weed seedbanks shows a positive correlation $\left(r^{2}=0.92\right)$ between seedling emergence and seed numbers (Fig. 2). This confirms the results of our earlier studies (Rahman et al. 1995), and demonstrates the potential for using the weed seed content of the soil to predict future weed problems, although correlation of individual species with field emergence still needs to be established.

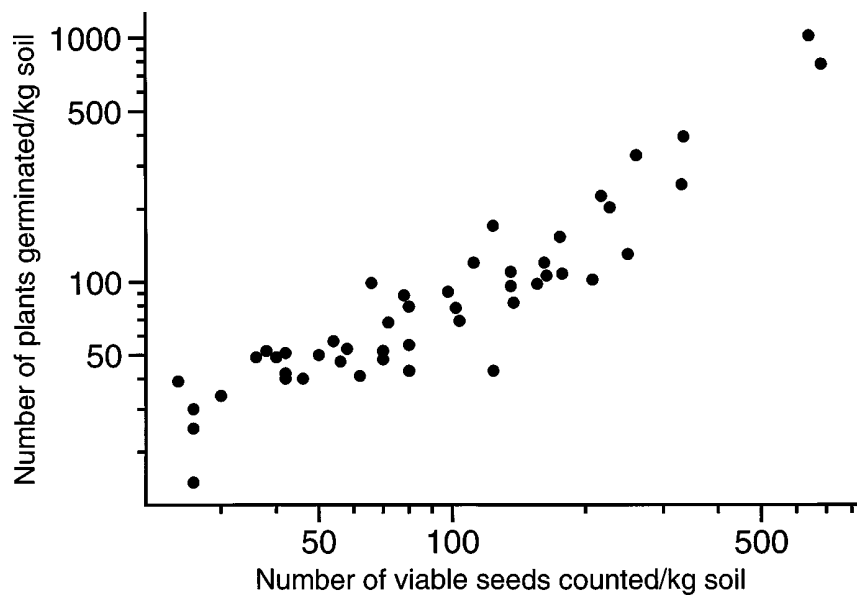

\section{FIGURE 2: Number of seedlings emerged (minus toad rush) versus the number of viable seeds found in each of the $\mathbf{4 8}$ individual soil samples.}

The total numbers of weed seeds and weed seedlings for each site are presented in Table 2. The numbers of seedlings were sometimes larger than the estimate of seed numbers. A possible reason for this could be the large numbers of toad rush seedlings, the seeds of which were not counted in the laboratory as they are small-sized, difficult to enumerate and were not considered to be of agronomic or economic significance in maize production (Rahman 1988).

\section{TABLE 2: Total seed and seedlings counted and total number of species found} in the inner and outer areas of each site.

\begin{tabular}{|c|c|c|c|c|c|c|c|c|}
\hline \multirow[b]{3}{*}{ Site } & \multicolumn{4}{|c|}{ Seedling emergence method } & \multicolumn{4}{|c|}{ Seed extraction method } \\
\hline & \multicolumn{2}{|c|}{ Total seedlings $/ \mathrm{kg}$} & \multicolumn{2}{|c|}{ No. of species } & \multicolumn{2}{|c|}{ Total seeds/kg } & \multicolumn{2}{|c|}{ No. of species } \\
\hline & In & Out & In & Out & In & Out & In & Out \\
\hline 1 & 71.9 & 141.3 & 19 & 30 & 36.5 & 141.0 & 12 & 22 \\
\hline 2 & 85.3 & 157.3 & 20 & 32 & 67.5 & 135.5 & 21 & 19 \\
\hline 3 & 417.0 & 545.4 & 18 & 29 & 343.3 & 394.0 & 13 & 15 \\
\hline 4 & 133.3 & 103.5 & 15 & 20 & 160.5 & 126.0 & 13 & 14 \\
\hline 5 & 49.6 & 95.5 & 19 & 24 & 40.0 & 87.5 & 15 & 18 \\
\hline 6 & 87.7 & 59.2 & 15 & 18 & 82.0 & 58.5 & 13 & 12 \\
\hline
\end{tabular}

There were no significant differences in the number of seeds or seedlings in samples collected from the outer and inner areas of fields. In field surveys of cereal crops in Britain, Wilson and Aebischer (1995) noted that numbers of species declined significantly between the crop edge and $4 \mathrm{~m}$ into the crop edge. Numbers remained 
stable as distance increased beyond $4 \mathrm{~m}$. The total number of seedlings of common broadleaf weeds also decreased significantly as distance from the crop edge increased. Other workers (Marshall 1989; Rew et al. 1992) have also recorded declining densities of most, but not all, weeds with increasing distance from the field edge. In our study the outer area chosen for sampling may have been too wide $(20 \mathrm{~m})$, but as the headland area is planted differently and sometimes has a poorly established crop, it was thought that it might be a distinguishable area. Similarly no significant differences in seed numbers were found in areas adjacent to drains, hedgerows, etc. (data not presented). Analysis of the data in Table 2 showed that overall there were significantly more weed species $(\mathrm{P}<0.05)$ in the outer than inner areas of fields for the seedling emergence method, although not in the case of the seed extraction method. The reason for this could be the larger size of samples used for the seedling emergence method ( 2 to 3 times of that used for seed extraction).

In total, 68 weed species were recorded, with the majority being found in very low numbers and many at only one site and often in only one or two areas within a site. This would indicate that there could be other weed species present at a site that were not found. Whether these might be of significance at some later date is open to conjecture. As the outermost strip of the field or the headland is usually cultivated, drilled, sprayed and harvested in a pattern different from that of the main part of the field, it is advisable to avoid these areas while collecting soil samples for weed seedbank estimates. Another interesting implication of these results mentioned by Wilson and Aebischer (1995) is that we must devise sympathetic management of the field margins in which the majority of weed populations still occur, if biodiversity of species is to be conserved.

\section{ACKNOWLEDGEMENTS}

The authors wish to thank the Seed Testing Station staff for the seed extractions, John Waller for the statistical analyses and Clyve Maley for technical assistance.

\section{REFERENCES}

Benoit, D.L., Derkson, D.A. and Panneton, B., 1992. Innovative approaches to seedbank studies. Weed Sci. 40: 660-669.

Bigwood, D.W. and Inouye, D.W., 1988. Spatial pattern analysis of seed-banks: an improved method and optimised sampling. Ecol. 69: 497-507.

Dessaint, F., Barralis, G., Beuret, E., Caixinhas, M.L., Post, B.J. and Zanin, G., 1990. EWRS collaborative study of seedbank estimation: I. Studies of the relation between the mean and the variance with sampling procedure. Weed Res. 30: 421429.

Forcella, F., Wilson, R.G., Renner, K.A., Dekker, J., Harvey, R.J., Alm, D.A., Buhler, D.D. and Cardina, J., 1992. Weed seedbanks of the U.S. Corn Belt: Magnitude, variation, emergence and application. Weed Sci. 40: 636-644.

Marshall, E.J.P., 1989. Distribution patterns of plants associated with arable field edges. J. Appl. Ecol. 26: 247-258.

Rahman, A., 1988. Recent major problems of weed control in maize in New Zealand. Med. Fac. Landbouww. Rijksumiv. Gent 53: 1335-1340.

Rahman, A. and James, T.K., 1993. Patterns of weed seedling emergence in two New Zealand soils. Proc. 8th EWRS Symposium, Braunschweig 1993: 665-672.

Rahman, A., James, T.K., Grbavac, N. and Mellsop, J., 1995. Evaluation of two methods for enumerating the soil weed seedbank. Proc. 48th N.Z. Plant Prot. Conf: : 175-180.

Rew, L.J., Wilson, P.J., Froud-Williams, R.J. and Boatman, N.D., 1992. Changes in vegetation composition and distribution within set-aside land. Set - aside. British Crop Prot. Council Monograph 50: 79-84.

Wilson, P.J. and Aebischer, N.J., 1995. The distribution of dicotyledonous arable weeds in relation to distance from the field edge. J. Appl. Ecol. 32: 295-310. 